\title{
Use of Cross-Fostering to Enhance Growth of Pigs That Are Predicted to Grow Poorly Based on Plasma $\alpha$-1 Acid Glycoprotein Concentration*
}

\author{
T. G. Ramsay\#, M. J. Stoll, L. L. Schreier, A. E. Shannon \\ Animal Biosciences and Biotechnology Laboratory, US Department of Agriculture, Agricultural Research Service, Beltsville, MD, USA \\ Email: "timothy.ramsay@ars.usda.gov
}

How to cite this paper: Ramsay, T.G., Stoll, M.J., Schreier, L.L. and Shannon, A.E. (2018) Use of Cross-Fostering to Enhance Growth of Pigs That Are Predicted to Grow Poorly Based on Plasma $\alpha$-1 Acid Glycoprotein Concentration. Open Journal of Animal Sciences, 8, 39-50.

https://doi.org/10.4236/ojas.2018.81004

Received: September 30, 2017

Accepted: December 17, 2017

Published: December 20, 2017

Copyright $\odot 2018$ by authors and Scientific Research Publishing Inc. This work is licensed under the Creative Commons Attribution International License (CC BY 4.0).

http://creativecommons.org/licenses/by/4.0/

\begin{abstract}
Porcine $\alpha$-1 acid glycoprotein (AGP) in newborn pigs can be used to predict growth rate through weaning and is a marker for growth impairment. This study examined whether nutritional support can improve the growth rate of piglets identified as having poor growth potential. Cross-fostering (CF) and CF plus a milk supplement (CF + MS) were used to attempt to improve the growth performance of pigs. Blood was collected at $\mathrm{d} 1$ post-parturition for measurement of plasma AGP for all pigs in 28 litters contributing to the experiment. Piglets with the highest plasma AGP level were weight and sex matched to a littermate with a low plasma AGP concentration and four pairs of these weight and sex matched pigs were grouped into four foster litters per treatment (control, $\mathrm{CF}, \mathrm{CF}+\mathrm{MS}$ ). The control group was assembled by pairing littermates remaining in donor litters. Pigs stayed on treatment until weaning at 21 days of age. At 35 days of age, dual energy X-ray absorptiometry (DXA) was performed on CF and CF + MS pigs to evaluate carcass composition. Control pairs differed in weaning weight, with pigs with higher plasma AGP at 1 day of age having smaller weaning weights than their littermates of similar birth weight $(P<0.05)$. However, CF eliminated the difference in weaning weight between the slow growing pigs and their birth weight matched littermates. $\mathrm{CF}+\mathrm{MS}$ produced a similar effect as $\mathrm{CF}(P>0.05)$. At 35 days of age, body weights were still similar between $\mathrm{CF}$ littermates and between $\mathrm{CF}+\mathrm{MS}$ littermates $(P>0.05)$. DXA analysis demonstrated that body composition was similar between $\mathrm{CF}$ or $\mathrm{CF}+\mathrm{MS}$ treated pigs and their litter-
\end{abstract}

*Mention of trade name, proprietary product or vendor does not constitute a guarantee or warranty of the product by the US Department of Agriculture or imply its approval to the exclusion of other products or vendors that also may be suitable. 
mates. These data demonstrate that CF can be used to correct the growth impairment in pigs predicted using plasma AGP as the marker. CF + MS can do the same, but at greater expense.

\section{Keywords}

Neonatal Pig, Alpha-1 Acid Glycoprotein, Cross-Fostering, Growth Rate, Body Composition

\section{Introduction}

Alpha-1 acid glycoprotein (AGP) is a negative acute phase protein that is highly expressed in the plasma of the newborn pig [1] [2]. Recent research has demonstrated that neonatal serum or plasma AGP can be used at birth to identify pigs that will grow poorly and can also be used to predict overall litter performance [2] [3]. The circulating concentration of AGP in the newborn is negatively correlated with postnatal growth rate up to 8 weeks of age [3]. Neonatal pigs of an average litter birth weight but with the highest circulating concentrations of AGP will grow more slowly than littermates of similar birth weight [2] and have a different body composition after weaning [4]. Previous research has demonstrated that pigs that grow poorly to weaning will not recover and will reach mature weight later than littermates [5] [6].

While AGP can function as a marker to identify neonatal pigs destined to grow poorly, the mechanisms responsible for why circulatory AGP can predict growth rate are unknown. Despite not knowing the mechanism, neonatal plasma AGP may be useful as a marker in studies to reverse the impaired growth of these pigs before we can detect a change in growth rate and assist these pigs to reach a weaning weight comparable to their normal growing littermates. A nutritional intervention is the simplest strategy to compensate for the initial growth impairment.

Cross-fostering of pigs has been a common and successful approach to enhancing growth in smaller pigs from large litters for many years [7] [8]. This is usually coupled with reducing the size of the litter to ensure adequate milk supply to all transferred pigs. However, questions have been raised as to whether the suckling intensity of these smaller litters is sufficient to promote adequate milk production by the sow [9]. Several studies have demonstrated that the sow does not provide adequate nutrition as early as in the second week post parturition [10] [11]. Therefore, a second strategy to improve the growth rate of these pigs may be by use of a milk supplement with cross-fostering. Feeding of a liquid milk replacer has been demonstrated to improve weaning weights in pigs [12] [13] [14]. If cross-fostering is inadequate to improve the nutritional status and growth rate of these poorly growing pigs, then the milk supplement may be necessary to ensure an improvement in weaning weight to littermates with normal growth performance. Therefore, this experiment was specifically designed to test 
the hypothesis that poor growth predicted by elevated plasma AGP in the newborn pig can be reversed by improving nutritional status so that these pigs can grow at similar weights as littermates with comparable birth weights.

\section{Materials and Methods}

Twenty eight Large White $\times$ Landrace (Fast 275, Fast Genetics, Ames IA) sows were used in this study. Only primiparous sows were used as biological and foster dams. These sows served as donors and recipients of piglets in order that none of the piglets evaluated remained with their biological dam after cross-fostering. Sows had free access to water and a corn-soybean meal based diet; dietary contents of metabolizable energy, protein, lysine, calcium, and phosphorus were $12.79 \mathrm{~kJ} / \mathrm{kg}, 15.1 \%, 0.72 \%, 0.98 \%$, and $0.57 \%$, respectively. All animal handling, animal procedures and euthanasia were approved by the USDA-ARS Institutional Animal Care and Use Committee of the Beltsville Agricultural Research Center. Data were collected over three farrowings in 2016. Farrowing occurred in March, June and September.

Farrowing crates were equipped with heated floor mats, a heat lamp, water nipples, a sow feeder and tenderfoot flooring (Tandem Products, Minneapolis $\mathrm{MN})$. Temperature in the farrowing facility was maintained at a minimum of $27^{\circ} \mathrm{C}-29^{\circ} \mathrm{C}$, and supplemental heat was provided to piglets with heat lamps as needed. Parturition was not assisted and piglets were permitted to find the teat on their own. On the first day after birth, tail-docking was performed and a 500 $\mu \mathrm{L}$ blood sample was collected from the tail vein using a centrifuge vial with integrated capillary (Microvette 500K3 EDTA, Sarstedt, Numbrecht, Germany). Needle teeth were trimmed on day 1, piglets were ear notched for identification and they also received injections of iron dextran (Iron Dextran Injection-200, Aspen Veterinary Resources, LTD, Liberty, MO). Finally, all piglets then received prophylactic antibiotics prior to returning them to their dam. Castration was performed on male pigs at 10 days of age.

Plasma samples prepared from the vials were used for analysis of AGP concentration on day 2 post farrowing by ELISA analysis [3]. Piglets were cross-fostered on day 3 at approximately 08:00 and distributed among the foster recipient sows in pairs according to their birth weight, gender and a difference in plasma AGP $>500 \mu \mathrm{g} / \mathrm{mL}$ [3]. In no case did a piglet suckle its own mother after cross-fostering. Foster litters consisted of piglets that were the same age and were comprised of four pairs of piglets. Recipient sows had their entire litter removed prior to transfer of the foster litters. Some piglets from recipient sows were used to replace the pair of pigs removed from the donor sow, so that litter size in the donors remained the same. A secondary weight and sex matched pair of piglets were identified in these donor sows and were used as controls for the cross-fostered pairs. Secondary pairs were comprised of littermates with a lower differential in plasma AGP but still with a difference in plasma AGP > 500 $\mu \mathrm{g} / \mathrm{mL}$. These control pairs were used to confirm the ability to identify neonatal 
pigs with the potential to grow poorly, based on plasma AGP. Excess piglets were euthanized by Euthasol injection (containing pentobarbital sodium and phenytoin sodium, Virbac AH, Inc., Fort Worth, TX). Three groups of sows were used, Group 1: a control group which had the same number of pigs as originally farrowed, following replacement of a selected pair allocated to groups 2 or 3. These ranged in size from 11 to 15 pigs; Group 2: a cross-foster group comprised of four pairs of pigs matched for birth weight and sex, but differing in plasma AGP concentration; Group 3: like group 2, but provided a supplemental milk replacer. Piglets did not have access to the sow's feed. General health of piglets was checked daily and use of medication was monitored. Two cross-fostered litters were removed from the study due to the death of one of the pair by crushing and the data were eliminated from the analysis. A replacement animal of similar age and weight was obtained from a sow not used in the study to maintain a litter size of eight.

For those litters receiving a milk supplement, liquid milk replacer was initially provided in bottles at 0700,1100 and 1500 hours. This was done to ensure that all cross-fostered pigs consume the milk replacer in those assigned litters. However, piglets during the first week consumed very limited supplement, we simply ensured each animal received some supplement. During the second week, fresh liquid milk replacer was provided daily ( 1000) to assigned pens in milk feeders (Kane Manufacturing, Pleasant Hill, IA). Milk feeders were thoroughly cleaned with detergent and hot water before the addition of fresh liquid milk replacer. Measurement of the volume of the remaining milk was attempted, but spillage/waste by the piglets prevented any accurate measure of intake. Milk replacer powder for piglets, consisting of dried bovine whey protein concentrate, dried whey, vegetable and animal fat, and lactose, was purchased from Land o' Lakes (Minneapolis, MN). The dietary composition is summarized in Table 1. Liquid milk replacer was prepared by diluting milk replacer powder ( $94.0 \%$ dry matter) 1:5 with warm water (dry matter $18.8 \%$ ). This is similar to the dry matter content (18.6\%) reported for sow's milk on d 7 - 21 of lactation [15].

Each cross-fostered litter (including those fed supplemental milk) was maintained as an individual group post weaning when transferred to nursery pens. Litters maintained on their original sow (controls) were mixed due to limitations on nursery space and were not evaluated after weaning. The nursery room has a concrete floor, self-feeders and nipple waterers. Temperature was maintained at $28^{\circ} \mathrm{C}-29^{\circ} \mathrm{C}$. Pigs were provided an identical diet consisting of corn and soybean meal supplemented with vitamins, minerals and salt; dietary contents of metabolizable energy, protein, lysine, calcium, and available phosphorus were 13.49 $\mathrm{kJ} / \mathrm{kg}, 17.4 \%, 1.19 \%, 1.02 \%$, and $0.66 \%$, respectively. The cross-fostered pigs were weighed 14 days post weaning ( 35 days of age) and dual energy X-ray absorptiometry (DXA) was used to measure body composition on the live animals according to the procedures of Mitchell et al., [4]. Pigs were anesthetized prior to scanning with a combination of ketamine $(30 \mathrm{mg} / \mathrm{kg})$ and xylazine $(2 \mathrm{mg} / \mathrm{kg})$ delivered by intramuscular injection. The scanning was performed using a DXA 
Table 1. Supplemental milk diet formulation ${ }^{1}$.

\begin{tabular}{ccc}
\hline & As packaged & As Fed $^{2}$ \\
\hline Protein & $24 \% \mathrm{~min}$ & $4.8 \% \mathrm{~min}$ \\
Lysine & $2.1 \% \mathrm{~min}$ & $0.4 \% \mathrm{~min}$ \\
Fat & $24 \% \mathrm{~min}$ & $4.8 \% \mathrm{~min}$ \\
Fiber & $0.15 \% \mathrm{max}$ & $0.03 \% \mathrm{max}$ \\
Moisture & $6.0 \% \mathrm{max}$ & - \\
$\mathrm{Ca}$ & $1 \%-1.25 \%$ & $0.2 \%-0.25 \%$ \\
$\mathrm{P}$ & $0.80 \% \mathrm{~min}$ & $0.16 \% \mathrm{~min}$ \\
$\mathrm{Na}$ & $0.5 \% \mathrm{to} 1.0 \%$ & $0.1 \%$ to $0.2 \%$ \\
$\mathrm{Cu}$ & $10-15 \mathrm{ppm}$ & $2-3 \mathrm{ppm}$ \\
$\mathrm{Se}$ & $0.3 \mathrm{ppm} \mathrm{min}$ & $0.06 \mathrm{ppm} \mathrm{min}$ \\
$\mathrm{Zinc}$ & $120 \mathrm{ppm} \mathrm{min}$ & $32 \mathrm{ppm} \mathrm{min}$ \\
$\mathrm{Vit}$ & $66,000 \mathrm{IU} / \mathrm{kg}$ & $13,200 \mathrm{IU} / \mathrm{kg}$ \\
$\mathrm{D} 3$ & $11,000 \mathrm{IU} / \mathrm{kg}$ & $2200 / \mathrm{kg}$ \\
$\mathrm{E}$ & $230 \mathrm{IU} / \mathrm{kg}$ & $46 \mathrm{IU} / \mathrm{kg}$ \\
\hline
\end{tabular}

${ }^{1}$ Land o' Lakes Pro-Nurse Multi-Species Milk Replacer (Minneapolis, MN). ${ }^{2}$ Diluted 1:5 with warm water to create an $18.8 \%$ DM liquid feeding supplement.

(GE Lunar Prodigy, GE Healthcare, Little Chalfont, UK) operating in the Small Animal Mode (ver. 8.10). Fat and lean contents reported by the DXA were corrected based on previous calibration studies using similar sized pigs and scan procedures [4]. The correction factor applied to the DXA fat measurement was as follows: \% Fat $=0.9608+(0.7135 \times$ DXA Fat $\%)$. The DXA lean measurement was then adjusted for the difference in the observed and calculated fat measurements. Data from the DXA analysis of one pig from a cross-fostered litter and one pig from a cross-fostered and milk supplemented pair were not successfully analyzed by DXA due to awakening from the anesthesia prior to completion of data capture, so data from their littermate was excluded from the body composition analysis.

\section{Statistics}

Paired t-test was used to compare the responses of paired littermates identified by a difference in plasma AGP $>500 \mu \mathrm{g} / \mathrm{mL}$. Analysis of variance was used to compare treatment groups when no specific effect of paired groups was identified with Tukey's method that was used to identify differences between the treatment groups (control, cross-fostered, supplemental milk). Statistical differences were defined at $P<0.05$.

\section{Results}

The use of plasma AGP to select for pigs that underperform relative to similar sized littermates at birth was examined in the control litters. These litters contained a birth weight and sex matched pair of piglets left on the sow with second 
largest differential in AGP measurement within that litter. Table 2 demonstrates that these pigs had similar birth weights but weaning weight and average daily gain (ADG) differed by approximately $10 \%(P<0.05)$. Plasma AGP concentrations differed by approximately $800 \mu \mathrm{g} / \mathrm{mL}$ in the pairs of piglets retained on their sow and with their original litter size $(P<0.001)$. Cross fostering removed performance differences. Cross-fostered pairs (group 2) were born at similar birth weights $(P>0.05)$ and had similar weaning weights $(P>0.05)$, despite a difference in plasma AGP level at day 1 of age of approximately $1800 \mu \mathrm{g} / \mathrm{mL}$. The littermate with a predicted normal growth curve in the cross-fostered pair had a nearly identical weaning weight as the normal littermate in the control pair. Only the littermate predicted to grow poorly had a change in weaning weight.

Cross-fostered litters supplemented with a liquid milk replacer had pairs of piglets with identical birth weights, similar weaning weights and similar ADG $(P>0.05)$. The only difference between cross-fostered pairs of pigs supplemented with milk was a difference in plasma AGP concentration of approximately $2500 \mu \mathrm{g} / \mathrm{mL}$. Following the weaning transition, cross-fostered pigs at day 35 of age did not demonstrate a difference in weight or ADG between day 21 and $35(P>0.05$, Table 3$)$. Similarly, pigs provided supplemental milk prior to weaning did not differ in weight at 35 days of age or ADG between day 21 and $35(P>0.05)$.

Table 2. Animal performance from birth to weaning (d21).

\begin{tabular}{|c|c|c|c|c|c|c|}
\hline & \multicolumn{2}{|c|}{ Control } & \multicolumn{2}{|c|}{ Cross-Fostered } & \multicolumn{2}{|c|}{ Cross-Fostered/Milk Fed } \\
\hline & Mean \pm SEM & $P$ Value & Mean \pm SEM & $P$ Value & Mean \pm SEM & $P$ Value \\
\hline \multicolumn{7}{|c|}{$\begin{array}{c}\text { Birth } \\
\text { Weight (kg) }\end{array}$} \\
\hline Slow & $1.50 \pm 0.05$ & $P>0.05$ & $1.59 \pm 0.05$ & $P>0.05$ & $1.53 \pm 0.05$ & $P>0.05$ \\
\hline Normal & $1.49 \pm 0.05$ & & $1.58 \pm 0.06$ & & $1.53 \pm 0.04$ & \\
\hline \multicolumn{7}{|c|}{$\begin{array}{c}\text { Weaning } \\
\text { Weight (kg) }\end{array}$} \\
\hline Slow & $6.39 \pm 0.27$ & $P<0.05$ & $7.53 \pm 0.34$ & $P>0.05$ & $9.69 \pm 0.41$ & $P>0.05$ \\
\hline Normal & $6.88 \pm 0.37$ & & $6.98 \pm 0.41$ & & $9.76 \pm 0.57$ & \\
\hline \multicolumn{7}{|c|}{$\begin{array}{c}\text { Average } \\
\text { Daily Gain }(\mathrm{kg} / \mathrm{d})\end{array}$} \\
\hline Slow & $0.23 \pm 0.01$ & $P<0.05$ & $0.28 \pm 0.01$ & $P>0.05$ & $0.39 \pm 0.02$ & $P>0.05$ \\
\hline Normal & $0.26 \pm 0.02$ & & $0.26 \pm 0.01$ & & $0.39 \pm 0.03$ & \\
\hline \multicolumn{7}{|c|}{$\begin{array}{c}\text { Plasma } \\
\text { AGP }(\mu \mathrm{g} / \mathrm{mL})\end{array}$} \\
\hline Slow & $3800 \pm 330$ & $P<0.001$ & $4850 \pm 560$ & $P<0.001$ & $5320 \pm 520$ & $P<0.001$ \\
\hline \multirow[t]{2}{*}{ Normal } & $2930 \pm 210$ & & $3000 \pm 260$ & & $2860 \pm 250$ & \\
\hline & ${ }^{1} \mathrm{n}=16$ pairs & & $\mathrm{n}=14$ pairs & & $\mathrm{n}=16$ pairs & \\
\hline
\end{tabular}

${ }^{1}$ Pairs represent littermate piglets (slow \& normal) of the same sex and birth weight, but are predicted to growth at different rates based upon differences in plasma AGP concentration at 1 day of age. 
Table 3. Animal performance post-weaning (d21 to d35 post-partum).

\begin{tabular}{ccccc}
\hline & \multicolumn{2}{c}{ Cross-Fostered } & \multicolumn{2}{c}{ Cross-Fostered/Milk Fed } \\
\cline { 2 - 5 } & Mean \pm SEM & $P$ Value & Mean \pm SEM & $P$ Value \\
\hline Weight at d35 $(\mathrm{kg})$ & & & & \\
Slow & $9.69 \pm 0.41$ & & $11.36 \pm 0.62$ & \\
Normal & $9.76 \pm 0.57$ & & $11.70 \pm 0.75$ & \\
Average Daily Gain (kg/d) & & & & \\
Slow & $0.16 \pm 0.01$ & & 0.05 & \\
Normal & $0.15 \pm 0.02$ & $P<0.05$ & $0.14 \pm 0.02$ & $P>0.05$ \\
& ${ }^{1} \mathrm{n}=14$ pairs & & $\mathrm{n}=16$ pairs & \\
\hline
\end{tabular}

${ }^{1}$ Pairs represent littermate piglets (slow \& normal) of the same sex and birth weight, but are predicted to growth at different rates based upon differences in plasma AGP concentration at 1 day of age.

Carcass composition was measured by DXA at $35 \mathrm{~d}$ of age, two weeks after weaning (Table 4). Pigs predicted to grow slow had similar body composition as littermates predicted to have normal growth rates following cross-fostering $(P>$ 0.05). Carcass composition was similar between pigs predicted to grow slow and their littermates following cross-fostering coupled with milk supplementation prior to weaning $(P>0.05)$. Pooling of data from fast and slow pigs within each management treatment and then comparing cross-fostering with or without milk feeding demonstrated that milk feeding produced more grams of lean tissue $(P<0.05)$, but this was due to a larger carcass $(P<0.05)$ as lean $\%$ was similar between the group only cross-fostered versus the group cross-fostered and supplemented milk $(P>0.05)$.

\section{Discussion}

Circulatory AGP predicts differences in growth rate at day 1 of age [2] [3]. This was confirmed in the present study with the control litters in which AGP predicted the lower growth rates of pigs with higher concentrations of plasma AGP. The impact of using plasma AGP to identify pigs that will grow poorly is somewhat blunted in the present study when examining the data from the control litters as the pigs selected for pairs in those litters demonstrated a much lower segregation of plasma AGP relative to pigs included in the cross-fostering and milk supplementation groups. This was the consequence of having already removed the weight matched pair of piglets with the highest segregation by plasma AGP at one day of age. We were left with using these secondary pairs as they were what was left in the litter after we removed the pigs with the highest differential in plasma AGP and more likely greater difference in growth rate [3]. Identification of a clear cutoff has not occurred to permit segregating which pigs above or below a certain plasma AGP concentration can be predicted to be poor performers or pigs with a more adequate growth rate early in postnatal life.

Reducing litter size and increasing teat and milk availability through cross-fostering can correct the observed growth deficiency in piglets with high 
Table 4. Carcass composition at $\mathrm{d} 35$ of age ${ }^{1}$.

\begin{tabular}{|c|c|c|c|c|c|}
\hline & \multicolumn{2}{|c|}{ Cross-Fostered } & \multicolumn{2}{|c|}{ Cross-Fostered/Milk Fed } & \multirow{2}{*}{$\begin{array}{c}\begin{array}{c}\text { Cross-Fostered } \\
\text { versus Milk Fed }\end{array} \\
P \text { Value }\end{array}$} \\
\hline & Mean \pm SEM & $P$ Value & Mean \pm SEM & $P$ Value & \\
\hline \multicolumn{6}{|l|}{ Fat $\%$} \\
\hline $\begin{array}{c}\text { Slow }^{2} \\
\text { Normal }\end{array}$ & $\begin{array}{l}11.8 \pm 0.8 \\
11.7 \pm 0.8\end{array}$ & $P>0.05$ & $\begin{array}{l}10.6 \pm 0.7 \\
11.0 \pm 0.7\end{array}$ & $P>0.05$ & $P>0.05$ \\
\hline \multicolumn{6}{|l|}{ Fat (g) } \\
\hline $\begin{array}{c}\text { Slow } \\
\text { Normal }\end{array}$ & $\begin{array}{l}974 \pm 119 \\
906 \pm 134\end{array}$ & $P>0.05$ & $\begin{array}{c}992 \pm 124 \\
1068 \pm 134\end{array}$ & $P>0.05$ & $P>0.05$ \\
\hline \multicolumn{6}{|l|}{ Lean \% } \\
\hline $\begin{array}{c}\text { Slow } \\
\text { Normal }\end{array}$ & $\begin{array}{l}86.8 \pm 0.8 \\
86.9 \pm 0.8\end{array}$ & $P>0.05$ & $\begin{array}{l}88.0 \pm 0.7 \\
87.9 \pm 0.8\end{array}$ & $P>0.05$ & $P>0.05$ \\
\hline \multicolumn{6}{|l|}{ Lean $(g)$} \\
\hline $\begin{array}{c}\text { Slow } \\
\text { Normal }\end{array}$ & $\begin{array}{l}6972 \pm 365 \\
6529 \pm 378\end{array}$ & $P>0.05$ & $\begin{array}{l}7978 \pm 497 \\
8213 \pm 513\end{array}$ & $P>0.05$ & $P<0.05$ \\
\hline \multicolumn{6}{|c|}{$\mathrm{BMD}\left(\mathrm{g} / \mathrm{cm}^{2}\right)$} \\
\hline $\begin{array}{l}\text { Slow } \\
\text { Normal }\end{array}$ & $\begin{array}{l}0.33 \pm 0.01 \\
0.31 \pm 0.01\end{array}$ & $P>0.05$ & $\begin{array}{l}0.36 \pm 0.01 \\
0.36 \pm 0.01\end{array}$ & $P>0.05$ & $P<0.05$ \\
\hline \multicolumn{6}{|l|}{$\mathrm{BMC}(\mathrm{g})$} \\
\hline $\begin{array}{c}\text { Slow } \\
\text { Normal }\end{array}$ & $\begin{array}{l}127 \pm 8 \\
117 \pm 9\end{array}$ & \multirow[t]{2}{*}{$P>0.05$} & $\begin{array}{c}144 \pm 9 \\
145 \pm 12\end{array}$ & \multirow[t]{2}{*}{$P>0.05$} & \multirow[t]{2}{*}{$P<0.05$} \\
\hline & $\mathrm{n}=13$ pairs & & $\mathrm{n}=15$ pairs & & \\
\hline
\end{tabular}

${ }^{1}$ Carcass composition was determined by dual energy X-ray absorptiometry (DXA) analysis on anesthetized pigs at 35 days of age. ${ }^{2}$ Pairs represent littermate piglets (slow \& normal) of the same sex and birth weight, but are predicted to growth at different rates based upon differences in plasma AGP concentration at 1 day of age. ${ }^{3}$ Data were pooled for pairs (slow, control) within each treatment and then compared. BMD $=$ Bone Mineral Density, BMC = Bone Mineral Content.

plasma AGP concentrations. So, is AGP a marker that can predict an inability to compete for nutrition? Previous research has indicated that pigs will focus on a specific teat for their nutrition for much of lactation [16] [17] [18] [19]. Posterior teats produce less milk, so piglets that nurse from those teats are smaller than those nursing from anterior teats with greater milk production [18] [19]. Litter hierarchy reorganization and a potential rearrangement in teat selection as the consequence of cross-fostering (with a reduction in litter size) appear to ensure an improved plane of nutrition to those pigs predicted to grow poorly when using plasma AGP at day 1 of age as the marker for poor growth rate. Thus, rearrangement of the litter hierarchy through cross-fostering may permit these piglets with a predicted lower growth potential to acquire a teat that is preferable along the teat line to provide more nutrition to support more growth.

An alternative hypothesis is that plasma AGP is a marker for adequate colo- 
strum intake. While AGP has not been detected in pig colostrum or milk [20], this does not mean that secretion of AGP by the pig liver cannot respond to various proteins or glycoproteins present in colostrum that are absorbed and pass through the liver, the site of most AGP synthesis [21]. Higher colostrum intake is associated with an increase in preweaning and post-weaning pig growth rate [22]. Piglets that are less competitive for teat selection and require more time prior to first consumption of colostrum [23] [24] may consume less colostrum during the first 24 hour post parturition and thus elicit a different response in hepatic AGP production or secretion than more competitive and vigorous piglets.

In association with being a potential marker for colostrum intake, the ability for plasma AGP from one day old pigs to predict potential growth rate in pigs through weaning and to eight weeks of age may also be related to the relative hepatic metabolic maturity at birth. Since the liver is the primary metabolic organ presented with nutrients from the milk following absorption, the plane of nutrition in relationship to the relative maturity of the hepatic metabolic and secretory functions at birth could have a significant impact on this nutrient sensing organ that results in variations in plasma AGP. Pigs that will grow more slowly have a higher plasma AGP concentration. The plasma levels of this protein in the present study are in the range of $2500-6000 \mu \mathrm{g} / \mathrm{mL}$; similar to our previous report [3]. Previous research has demonstrated that AGP is present in the plasma of the newborn pig at the highest concentration for any protein, including albumin [25]. The very high rate of AGP protein synthesis and thus energy use suggests that there is some metabolic dysregulation present at birth in the pig that has a high potential to grow poorly relative to littermates. Cross-fostering with realignment of teat preference and the subsequent improvement in nutritional plane causes a compensation for this metabolic dysregulation so that growth impairment is overcome.

Milk supplements are very effective in providing additional nutrition, especially in the later stages of lactation when the sow can no longer support the demands of the offspring for energy and nutrients for protein and fat accretion. The present study confirms this, since cross-fostered pigs receiving milk supplements had higher weaning weight and more grams of lean tissue, but a similar lean $\%$ as pigs not receiving supplemental milk. Wolter et al. [14] demonstrated that providing milk replacer to litters of pigs improved litter weaning weight; however, the weight gain of all animals was proportional (as all were provided the milk replacer) so weaning weight variability was still present as in untreated litters. Since the present study specifically targeted the animals predicted to grow more slowly prior to any difference in body weight (weight differences cannot be detected until 7 days of age, manuscript in submission), the impact of supplemental nutrition is similar between the pigs with potential to grow slow and their littermates of similar birth weight.

The net effect of using AGP to predict poor piglet performance is that it pro- 
vides a marker for a relatively inexpensive method, in terms of cost and labor, to improve performance to that of normal growing littermates with cross-fostering. Interestingly, the faster growing littermates did not respond to cross-fostering with any improvement in weaning weight relative to control pigs in larger litters. This suggests that they have reached a metabolic limit on tissue accretion with the substrates available to them from suckling. A higher accretion rate requires dietary supplementation. Cross-fostering is effective in eliminating the difference in growth performance between pigs predicted to grow slow versus littermates based upon plasma AGP concentration. Providing a liquid milk supplement has no added benefit, relative to cross-fostering, for eliminating the growth deficit and a much higher cost in both expense of the supplement and the increased labor necessary to ensure cleanliness of the milk feeders. The apparent benefit of the milk supplement in the present study was to increase overall weight of all animals at weaning.

\section{Acknowledgements}

We wish to thank the Beltsville Agricultural Research Center farm staff for their assistance with this project.

\section{References}

[1] Martin, M., Tesouro, M.A., Gonz, A.N., Pi, A. and Lampreave, F. (2005) Major Plasma Proteins in Pig Serum During Postnatal Development. Reproduction Fertility and Development, 17, 439-445. https://doi.org/10.1071/RD04064

[2] Caperna, T.J., Shannon, A.E., Blomberg, L.A., Stoll, M. and Ramsay, T.G. (2013) Identification of Alpha-1 Acid Glycoprotein (AGP) as a Potential Marker of Impaired Growth in the Newborn Piglet. Reproduction, Fertility and Development, 25, 1126-1123. https://doi.org/10.1071/RD12103

[3] Caperna, T.J., Shannon, A.E., Stoll, M., Kahl, S., Blomberg, L.A., Vallet, J.L. and Ramsay, T.G. (2017) A Sandwich ELISA for Porcine Alpha-1 Acid Glycoprotein (pAGP, ORM-1) and Further Demonstration of its Use to Evaluate Growth Potential in Newborn Pigs. Domestic Animal Endocrinology, 60, 75-82. https://doi.org/10.1016/j.domaniend.2017.04.001

[4] Mitchell, A.D., Ramsay, T.G., Caperna, T.J. and Scholz, A.M. (2012) Body Composition of Piglets Exhibiting Different Growth Rates. Archives Animal Breeding, 55, 356-363. https://doi.org/10.5194/aab-55-356-2012

[5] Mahan, D.C. and Lepine, A.J. (1991) Effect of Pig Weaning Weight and Associated Nursery Feeding Programs on Subsequent Performance to 105 Kilograms Body Weight. Journal of Animal Science, 69, 1370-1378. https://doi.org/10.2527/1991.6941370x

[6] Cabrera, R.A., Boyd, R.D., Jungst, S.B., Wilson, E.R., Johnston, M.E., Vignes, J.L., and Odle J. (2010) Impact of Lactation Length and Piglet Weaning Weight on Long-Term Growth and Viability of Progeny. Journal of Animal Science, 88, 2265-2276. https://doi.org/10.2527/jas.2009-2121

[7] England, D.C. (1986) Improving Sow Efficiency by Management to Enhance Opportunity for Nutritional Intake by Neonatal Piglets. Journal of Animal Science, 63, 1297-1306. https://doi.org/10.2527/jas1986.6341297x 
[8] Koketsu, Y., Tani, S. and Iida, R. (2017) Factors for Improving Reproductive Performance of Sows and Herd Productivity in Commercial Breeding Herds. Porcine Health Management, 3, 1. https://doi.org/10.1186/s40813-016-0049-7

[9] King, R.H. (2000) Factors That Influence Milk Production in Well-Fed Sows. Journal of Animal Science, 78, 19-25. https://doi.org/10.2527/2000.78suppl_319x

[10] Boyd, R.D., Kensinger, R.S., Harrell, R.J. and Bauman, D.E. (1995) Nutrient Uptake and Endocrine Regulation of Milk Synthesis by Mammary Tissue of Lactating Sows. Journal of Animal Science, 73, 36-56. https://doi.org/10.2527/1995.73suppl_236x

[11] Boyd, R.D. and Kensinger, R.S. (1998) Metabolic Precursors for Milk Synthesis. In: Verstegen, M.W.A., Moughun, P.J. and Schrama, J.W., Eds., The Lactating Sow, Wageningen Press, Wageningen, 71.

[12] Azain, M.J., Tomkins, T., Sowinski, J.S., Arentson, R.A. and Jewell, D.E. (1996) Effect of Supplemental Pig Milk Replacer on Litter Performance: Seasonal Variation in Response. Journal of Animal Science, 74, 2195-2202.

https://doi.org/10.2527/1996.7492195x

[13] Dunshea, F.R., Kerton, D.J., Eason, P.J. and King, R.H. (1999) Supplemental Skim Milk before and after Weaning Improves Growth Performance of Pigs. Australian Journal of Agricultural Research, 50, 1165-1170. https://doi.org/10.1071/AR98208

[14] Wolter, B.F., Ellis, M., Corrigan, B.P. and DeDecker, J.M. (2002) The Effect of Birth Weight and Feeding of Supplemental Milk Replacer to Piglets during Lactation on Preweaning and Postweaning Growth Performance and Carcass Characteristics. Journal of Animal Science, 80, 301-308. https://doi.org/10.2527/2002.802301x

[15] Rezaei, R., Knabe, D.A., Tekwe, C.D., Dahanayaka, S., Ficken, MD., Fielder, S.E., Eide, S.J. and Lovering, S.L. and Wu, G. (2013) Dietary Supplementation with Monosodium Glutamate is Safe and Improves Growth Performance in Postweaning Pigs. Amino Acids, 44, 911-923. https://doi.org/10.1007/s00726-012-1420-x

[16] McBride, G. (1963) The "Teat Order" and Communication in Young Pigs. Animal Behavior, 11, 53-56. https://doi.org/10.1016/0003-3472(63)90008-3

[17] Hartsock, T.G., Graves, H.B. and Baumgardt, B.R. (1977) Agonistic Behavior and the Nursing Order in Suckling Piglets: Relationships with Survival, Growth and Body Composition. Journal of Animal Science, 44, 320-330. https://doi.org/10.2527/jas1977.442320x

[18] Pluske, J.R. and Williams, I.H. (1996) Split Weaning Increases the Growth of Light Piglets during Lactation. Australian Journal of Agricultural Research, 47, 513-523. https://doi.org/10.1071/AR9960513

[19] Kim, S.W., Hurley, W.L., Han, I.K. and Easter, R.A. (2000) Growth of Nursing Pigs Related to the Characteristics of Nursed Mammary Glands. Journal of Animal Science, 78, 1313-1318. https://doi.org/10.2527/2000.7851313x

[20] Guiraudie-Capraz, G., Slomianny, M.C., Pageat, P., Malosse, C., Cain, A.H., Orgeur, P. and Nagnan-Le Meillour, P. (2005) Biochemical and Chemical Supports for a Transnatal Olfactory Continuity through Sow Maternal Fluids. Chemical Senses, 30, 241-251. https://doi.org/10.1093/chemse/bji020

[21] Fournier, T., Medjoubi, N.N. and Porquet, D. (2000) Alpha-1-Acid Glycoprotein. Biochimica Biophysica Acta, 482, 157-171. https://doi.org/10.1016/S0167-4838(00)00153-9

[22] Declerck, I., Dewulf, J., Sarrazin, S. and Maes, D. (2016) Long-Term Effects of Colostrums Intake in Piglet Mortality and Performance. Journal of Animal Science, 94, 1633-1643. https://doi.org/10.2527/jas.2015-9564 
[23] Rooke, J.A. and Bland, I.M. (2002) The Acquisition of Passive Immunity in the New-Born Piglet. Livestock Production Science, 78, 13-23. https://doi.org/10.1016/S0301-6226(02)00182-3

[24] Le Dividich, J., Rooke, J.A. and Herpin, P. (2005) Review: Nutritional and Immunological Importance of Colostrum for the New-Born Pig. Journal of Agricultural Science, 143, 469-485. https://doi.org/10.1017/S0021859605005642

[25] Lampreave, F. and Piñeiro, A. (1984) The Major Serum Protein of Fetal and Newborn Pigs: Biochemical Properties and Identification as a Fetal Form of Alpha 1-Acid Glycoprotein. International Journal of Biochemistry, 16, 47-53.

https://doi.org/10.1016/0020-711X(84)90049-1 